NOTE BREVI

\title{
On a Possible Seasonal Tidal Influence of Lunar Cycles on Precipitation Data (Erratum).
}

G. Cevolani and G. Bortolotti

FISBAT/CNR, via Castagnoli 1 - 40126 Bologna, Italia

(Nuovo Cimento C, 10, 593 (1987))

PACS. 92.60. - Meteorology.

Figure $2 b$ ) on page 597 has been erroneously turned. We publish hereby the correct figure.
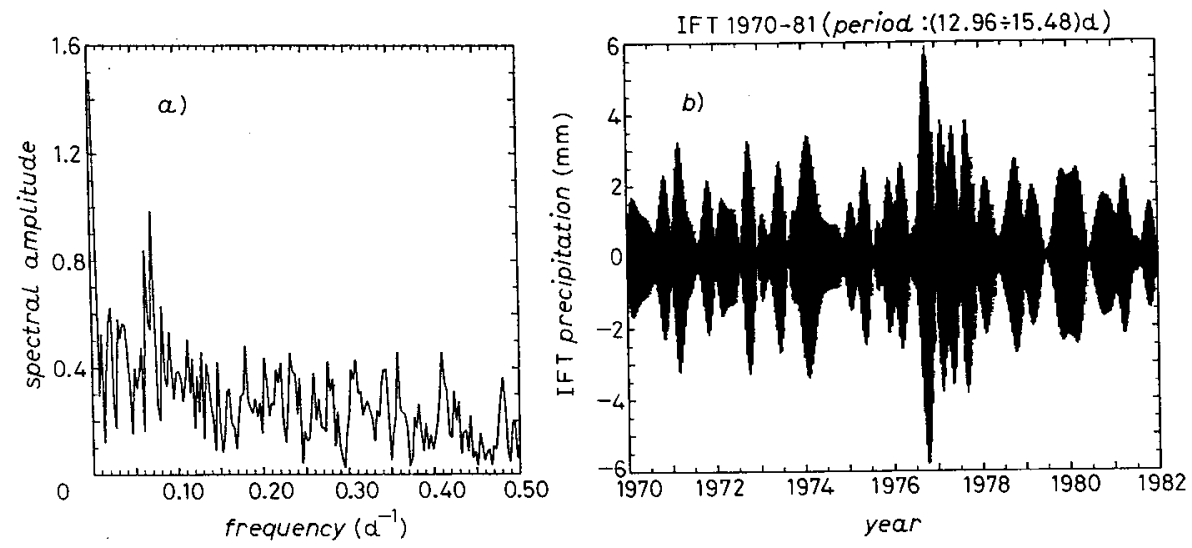

Fig. 2. - a) Amplitude spectrum of the Fourier transform of the daily data series in 1976; b) time variations of the amplitude maxima of a "semi-monthly" component throughout the 1970-81 observing period, by using the inverse Fourier transform (ENEL data). 